\title{
Cytokine and chemokine response in children with the 2009 pandemic influenza $A$ (H1N1) virus infection
}

\author{
T. Takano • H. Tajiri • Y. Kashiwagi • S. Kimura • \\ H. Kawashima
}

Received: 12 March 2010 /Accepted: 4 August 2010 /Published online: 6 September 2010

(C) The Author(s) 2010. This article is published with open access at Springerlink.com

\begin{abstract}
We report the systemic cytokine and chemokine response in children with the 2009 pandemic influenza A (H1N1) virus infection. In patients with pneumonia, the serum levels of IFN- $\gamma$ and IL-5 were significantly higher than those in patients without pneumonia. This tendency was also present for IL-6, IL-8, IL-10, IL-13, and MCP-1 in patients with pneumonia. Among patients with pneumonia, the levels of MCP-1 were significantly higher in the group of patients with pneumonia with severe respiratory failure than patients with mild pneumonia.
\end{abstract}

\section{Introduction}

In late March and early April 2009, an outbreak of the 2009 pandemic influenza $A(H 1 N 1)$ virus infection was detected in Mexico, with subsequent cases observed in many countries, including the United States [1]. It was reported that the 2009 H1N1 virus was identified as the cause of outbreaks of febrile respiratory infection ranging from selflimited to severe illness, and there were severe cases that developed respiratory failure [2]. Cytokine responses to influenza virus infection have been shown to contribute to the pathogenesis and severity of influenza virus infection, particularly influenza-associated encephalopathy (H1N1, $\mathrm{H} 3 \mathrm{~N} 2$ ) and respiratory failure (H5N1) [3-5]. However, the

T. Takano $(\bowtie) \cdot$ H. Tajiri $\cdot$ S. Kimura

Department of Pediatrics, Osaka General Medical Center,

3-1-56 Bandai-Higashi, Sumiyoshi-ku,

Osaka 558-8558, Japan

e-mail: takano@gh.opho.jp

Y. Kashiwagi $\cdot$ H. Kawashima

Department of Pediatrics, Tokyo Medical University,

Tokyo, Japan cytokine response during the $2009 \mathrm{H} 1 \mathrm{~N} 1$ virus infection is poorly understood. Therefore, we evaluated the systemic cytokine and chemokine response during the 2009 H1N1 virus infection and studied the expression of cytokines and chemokines in pediatric patients with pneumonia, one of the major complications of the disease.

\section{Methods}

Thirty-four children with the $2009 \mathrm{H} 1 \mathrm{~N} 1$ virus infection who were admitted to our center between July and December 2009 were included in this study. There were 25 boys and 9 girls, and their ages ranged from 2 to 11 years, with a median age of 6 years. 2009 H1N1 virus infection was confirmed by the detection of the viral genomes with the real time reverse transcription polymerase chain reaction (RT-PCR) assay targeted at a region of swine H1 HA gene using a nasal swab specimen obtained at the time of admission. Twenty-one children with the 2009 H1N1 virus infection had pneumonia with abnormal respiratory signs (weakness of breath sound, wheezing, and hypoxia) and definite consolidation shadows or atelectasis in their chest X-ray examinations, while another 13 patients presented without pneumonia, including vomiting [6], delirium [4], convulsion [1], liver dysfunction [1], and pancytopenia [1]. Among 21 patients with pneumonia, 10 patients had severe pneumonia with respiratory failure; all patients were admitted to an intensive care unit (ICU) and 5 of the 10 patients required mechanical ventilation. Seven of the 10 patients with severe pneumonia had lobar or multilobar atelectasis with consolidation shadow in their chest x-ray examination. Another 11 patients with pneumonia had mild respiratory disorder, and none of them had an ICU admission or underwent mechanical ventilation. 
The concentrations of cytokines and chemokines in the serum obtained at the time of admission, which was within the first 4 days after symptoms onset, were measured. We assayed 17 cytokines in serum (IL-1 $\beta$, IL-2, IL-4, IL-5, IL6, IL-7, IL-8, IL-10, IL-12, IL-13, IL-17, G-CSF, GM-CSF, IFN- $\gamma$, MCP-1, MIP-1 $\beta$, and TNF- $\alpha$ ) by the Bio-Plex suspension array system and the 17-Plex Panel (Bio-Rad Laboratories, Tokyo, Japan). The Mann-Whitney $U$-test was used for the statistical comparison of the two groups of patients. $p$-values less than 0.01 were considered to be significant in this study. The Institutional Review Board of our center approved the protocols of the study. Written

Table 1 Patient characteristics

\begin{tabular}{|c|c|c|c|}
\hline & & Patients with pneumonia $(n=21)$ & Patients without pneumonia $(n=13)$ \\
\hline \multicolumn{2}{|l|}{ Age (years) } & $8(2-11)$ & $6(2-10)$ \\
\hline \multicolumn{2}{|l|}{ Male sex (no.) } & 15 & 10 \\
\hline \multicolumn{2}{|l|}{ Illness day on admission (day) } & $2(1-4)$ & $2(1-3)$ \\
\hline \multirow[t]{6}{*}{ Underlying medical conditions } & Asthma (no.) & 7 & 1 \\
\hline & Seizure disorder (no.) & 1 & 2 \\
\hline & Neurological disorders (no.) & 0 & 1 \\
\hline & Renal disease (no.) & 1 & 0 \\
\hline & Heart disease (no.) & 0 & 1 \\
\hline & Obesity (no.) & 0 & 1 \\
\hline \multirow[t]{7}{*}{ Clinical signs and symptoms } & Fever (no.) & 21 & 13 \\
\hline & Cough (no.) & 21 & 9 \\
\hline & Vomiting (no.) & 0 & 6 \\
\hline & Delirium (no.) & 1 & 4 \\
\hline & Convulsion (no.) & 0 & 1 \\
\hline & Liver dysfunction (no.) & 0 & 1 \\
\hline & Pancytopenia (no.) & 0 & 1 \\
\hline \multirow[t]{6}{*}{ Respiratory complications } & $\mathrm{RR}(/ \mathrm{min})$ & $40(24-65)$ & $28(27-40)$ \\
\hline & $\mathrm{SpO}_{2}(\%)$ & $89(82-96)$ & $97(95-99)$ \\
\hline & Weakness of breath sound (no.) & 10 & 0 \\
\hline & Wheezing (no.) & 6 & 0 \\
\hline & Hypoxia (no.) & 21 & 0 \\
\hline & Bacterial pneumonia (no.) & 2 & 0 \\
\hline \multirow[t]{3}{*}{ Chest X-ray } & Consolidation: unilateral (no.) & $15 / 21$ & $0 / 5$ \\
\hline & bilateral (no.) & $4 / 21$ & \\
\hline & Atelectasis (no.) & $8 / 21$ & $0 / 5$ \\
\hline \multirow[t]{5}{*}{ Outcome } & Oxygen requirement (no.) & 21 & 0 \\
\hline & ICU admission (no.) & 10 & 0 \\
\hline & Use of mechanical ventilation (no.) & 5 & 0 \\
\hline & Death & 0 & 0 \\
\hline & Duration of hospitalization (day) & $6(4-12)$ & $5(2-6)$ \\
\hline \multirow[t]{8}{*}{ Laboratory results } & WBC $\left(\times 10^{3} / \mu \mathrm{l}\right)$ & $9.7(1.8-23.6)$ & $6.9(2.6-10.3)$ \\
\hline & Ht $(\%)$ & $37.8(35.6-44.2)$ & $36.3(33.2-41.8)$ \\
\hline & Plt $\left(\times 10^{4} / \mu 1\right)$ & $22.2(13.0-70.3)$ & $20.8(8.5-30.1)$ \\
\hline & CRP (mg/dl) & $2.8(0.3-8.6)$ & $0.7(0.1-2.7)$ \\
\hline & $\operatorname{AST}(\mathrm{U} / 1)$ & $29(15-48)$ & $35(26-485)$ \\
\hline & ALT(U/1) & $13(4-53)$ & $14(9-267)$ \\
\hline & $\mathrm{LD}(\mathrm{U} / \mathrm{l})$ & $294(220-402)$ & $318(231-714)$ \\
\hline & CK (U/1) & $125(9-248)$ & $87(43-896)$ \\
\hline
\end{tabular}

Data are given as medians (range) 
Table 2 Level of cytokines and chemokines in the serum. Comparison between patients with pneumonia and those without pneumonia

\begin{tabular}{llll}
\hline & $\begin{array}{l}\text { Patients with } \\
\text { pneumonia }(n=21)\end{array}$ & $\begin{array}{l}\text { Patients without } \\
\text { pneumonia }(n=13)\end{array}$ & $p$-value \\
\hline IL-1 $\beta$ & -0.2 (und.-1.4) & -0.9 (und.-2.6) & 0.392 \\
IL-2 & 1.0 (und.-2.3) & 0.4 (und.-1.8) & 0.150 \\
IL-4 & -0.1 (und.-0.7) & und. (und.-0.8) & 0.159 \\
IL-5 & 1.0 (und.-2.5) & und. (und.-0.8) & $<0.001$ \\
IL-6 & 1.8 (und.-3.4) & 0.7 (-0.4-2.5) & 0.035 \\
IL-7 & 0.1 (und.-1.5) & 0.3 (und.-1.7) & 0.394 \\
IL-8 & 1.1 (0.1-1.7) & 0.5 (-0.6-1.7) & 0.021 \\
IL-10 & 1.2 (und.-2.3) & und. (und.-2.1) & 0.023 \\
IL-12 & -0.3 (und.-2.2) & und. (und.-1.4) & 0.176 \\
IL-13 & -0.2 (und.-1.4) & und. (und.-0.5) & 0.020 \\
IL-17 & und. (und.-1.9) & und. & 0.590 \\
G-CSF & 1.3 (und.-2.4) & 0.7 (und.-2.1) & 0.068 \\
GM-CSF & 1.3 (und.-2.7) & 0.3 (und.-2.4) & 0.282 \\
IFN- $\gamma$ & 2.2 (und.-3.8) & 1.5 (und.-3.2) & 0.009 \\
MCP-1 & 2.1 (und.-3.2) & 1.4 (und.-2.5) & 0.035 \\
MIP-1 $\beta$ & 1.7 (0.1-2.5) & 1.1 (0-2.7) & 0.074 \\
TNF- $\alpha$ & 1.4 (und.-2.4) & und. (und.-2.2) & 0.109 \\
\hline Dat & & &
\end{tabular}

Data are given as median $\log _{10}$ pg per $\mathrm{ml}$ (range)

und., undetectable

informed consent was obtained from all patients or their guardians.

\section{Results}

Among the patients who presented with the 2009 H1N1 virus infection, there were no differences in the age, sex, or illness day on admission between patients with pneumonia and those without pneumonia (Table 1). The patients with pneumonia were more likely to have asthma as an underlying medical condition, oxygen administration, ICU admission, and mechanical ventilation than patients without pneumonia. Two patients with pneumonia showing leukocytosis and elevated C-reactive protein (CRP) were suspected to have a bacterial coinfection, but cultures of sputum or nasopharyngeal swabs were not done.

Among measured cytokines and chemokines in the children during the $2009 \mathrm{H} 1 \mathrm{~N} 1$ virus infection, the serum levels of IFN- $\gamma$ and IL-5 in patients with pneumonia were significantly higher than those in patients without pneumonia. This tendency was also present for the serum levels of IL-6, IL-8, IL-10, IL-13, and MCP-1 in patients with pneumonia (Table 2).

The serum levels of IL- $1 \beta$, IL- 2 , IL- 4 , and MCP-1 were significantly higher in the group of patients with severe pneumonia than in those with mild pneumonia (Table 3 ). This tendency was also present for IL-5, IL-13, and TNF- $\alpha$, although it was not observed with the levels of IL-6, IFN- $\gamma$, and other chemokines, such as IL- 8 and MIP-1 $\beta$.

\section{Discussion}

This study shows that the serum levels of IFN- $\gamma$, IL-5, IL-6, IL-8, IL-10, IL-13, and MCP-1 in patients with pneumonia were higher than that in patients without pneumonia during the $2009 \mathrm{H} 1 \mathrm{~N} 1$ virus infection. The levels of IL-1 $\beta$, IL-2, IL-4, and MCP-1 were significantly different between patients with severe pneumonia and those with mild pneumonia. Of note, MCP-1 was especially higher in patients with severe pneumonia who developed respiratory failure. These findings suggest that MCP-1 might contribute to the pathogenesis and severity of respiratory complications in the $2009 \mathrm{H} 1 \mathrm{~N} 1$ virus infection or the degree of MCP-1 production could reflect the severity of the infection. In this regard, it is intriguing that the MCP-1 knockout mice had a reduced antiviral clearance, together with reduced leukocytes recruitment into the lungs during infection with influenza $\mathrm{A}$ [6]. In patients with severe pneumonia caused by influenza

Table 3 Level of cytokines and chemokines in the serum. Comparison between patients with severepneumonia and those with mild pneumonia

\begin{tabular}{llll}
\hline & Pneumonia & & \\
\cline { 2 - 3 } & Severe $(n=10)$ & Mild $(n=11)$ & \\
\hline IL-1 $\beta$ & und. (und.-1.4) & und. (und.-0.7) & 0.005 \\
IL-2 & $1.4(-0.2-2.3)$ & 0.8 (und.-1.5) & 0.009 \\
IL-4 & 0.5 (und.-0.7) & und. (und.-0.6) & 0.008 \\
IL-5 & $1.6(-1.2-2.5)$ & 0 (und.-2.4) & 0.024 \\
IL-6 & $2.1(0.4-3.4)$ & 1.5 (und.-2.4) & 0.078 \\
IL-7 & 0.2 (und.-1.5) & -0.1 (und.-1.5) & 0.698 \\
IL-8 & 1.1 (0.2-1.6) & 1.1 (0.1-1.7) & 0.725 \\
IL-10 & 1.4 (und.-2.3) & 0.4 (und.-1.7) & 0.075 \\
IL-12 & 0.9 (und.-2.2) & und. (und.-1.1) & 0.060 \\
IL-13 & 0.9 (und.-1.4) & -1.0 (und.-1.0) & 0.027 \\
IL-17 & und. (und.-1.9) & und. & 0.056 \\
G-CSF & 1.5 (und.-2.4) & 1.1 (und.-2.2) & 0.379 \\
GM-CSF & 1.6 (und.-2.7) & 0.5 (und.-1.9) & 0.056 \\
IFN- $\gamma$ & 2.5 (und.-3.8) & 1.9 (und.-3.3) & 0.091 \\
MCP-1 & 2.5 (1.0-3.2) & 1.5 (und.-2.4) & 0.007 \\
MIP-1 $\beta$ & 1.8 (0.5-2.5) & 1.5 (0.1-2.5) & 0.105 \\
TNF- $\alpha$ & 2.5 (und.-2.4) & -0.1 (und.-2.0) & 0.038 \\
\hline
\end{tabular}

Data are given as median $\log _{10}$ pg per ml (range)

und., undetectable 
A (H5N1) infection, the levels of several chemokines, such as IP-10, MIG, MCP-1, and IL-8, in the peripheral blood were elevated and particularly high in those with fatal outcome [5]. Experimental data in a human lung organ culture model showed that influenza viruses $(\mathrm{H} 1 \mathrm{~N} 1$ and H3N2) proliferated in the bronchial epithelial cells and induced the production of MCP-1, MIP-1, IL-8, and IP-10 [7]. On the other hand, in pigs infected by the 2009 H1N1 virus, the levels of IL-6, IFN- $\alpha$, and TNF- $\alpha$ in the bronchoalveolar lavage fluid were elevated, but the concentrations of chemokines were not measured [8] and the roles of chemokines in respiratory complications of the $2009 \mathrm{H} 1 \mathrm{~N} 1$ virus infection remains to be investigated. We speculate that the 2009 H1N1 virus proliferates in the bronchial epithelial cells in patients and induces the production of several chemokines, which cause the inflammation of the airway, followed by severe respiratory complications.

Influenza-associated encephalopathy is a severe neurologic complication of influenza virus infection [9]. Although the pathogenesis of this complication is still unclear, the serum levels of proinflammatory cytokines, including IL-1 $\beta$, IL- 6 , and TNF- $\alpha$, have been shown to be elevated and related to the clinical severity of $[3,4]$. Among patients with this type of encephalopathy, the serum TNF- $\alpha$ values at onset were significantly higher in patients who died compared to those who survived [3, 4]. The present study shows a characteristic cytokine profile in the patients with pneumonia during the $2009 \mathrm{H} 1 \mathrm{~N} 1$ virus infection which is different from what is observed in influenza-associated encephalopathy. The secretion of cytokines and chemokines during the acute phase of the 2009 H1N1 virus infection were clearly different depending on the presenting symptoms. This suggests that an early-phase response of cytokines and chemokines during the 2009 H1N1 virus infection might have contributed to the pathogenesis of the disease. In conclusion, the present study shows that the production of several chemokines, especially MCP-1, may have a role in the pathogenesis of respiratory complications during the 2009 H1N1 virus infection.

Open Access This article is distributed under the terms of the Creative Commons Attribution Noncommercial License which permits any noncommercial use, distribution, and reproduction in any medium, provided the original author(s) and source are credited.

\section{References}

1. Khan K, Arino J, Hu W et al (2009) Spread of a novel influenza A (H1N1) virus via global airline transportation. N Engl J Med 361:212-214

2. Perez-Padilla R, de la Rosa-Zamboni D, Ponce de Leon S et al (2009) Pneumonia and respiratory failure from swine-origin influenza A (H1N1) in Mexico. N Engl J Med 361:680-689

3. Kawada J, Kimura H, Ito Y et al (2003) Systemic cytokine responses in patients with influenza-associated encephalopathy. J Infect Dis 188:690-698

4. Hosoya M, Nunoi H, Aoyama M et al (2005) Cytochrome c and tumor necrosis factor-alpha values in serum and cerebrospinal fluid of patients with influenza-associated encephalopathy. Pediatr Infect Dis J 24:467-470

5. de Jong MD, Simmons CP, Thanh TT et al (2006) Fatal outcome of human influenza A (H5N1) is associated with high viral load and hypercytokinemia. Nat Med 12:1203-1207

6. Dessing MC, van der Sluijs KF, Florquin S, van der Poll T (2007) Monocyte chemoattractant protein 1 contributes to an adequate immune response in influenza pneumonia. Clin Immunol 125:328336

7. Wu W, Booth JL, Duggan ES et al (2010) Innate immune response to $\mathrm{H} 3 \mathrm{~N} 2$ and $\mathrm{H} 1 \mathrm{~N} 1$ influenza virus infection in a human lung organ culture model. Virology 396:178-188

8. Van Reeth K, Nauwynck H, Pensaert M (1998) Bronchoalveolar interferon-alpha, tumor necrosis factor-alpha, interleukin-1, and inflammation during acute influenza in pigs: a possible model for humans? J Infect Dis 177:1076-1079

9. Morishima T, Togashi T, Yokota S et al; Collaborative Study Group on Influenza-Associated Encephalopathy in Japan (2002) Encephalitis and encephalopathy associated with an influenza epidemic in Japan. Clin Infect Dis 35:512-517 